\title{
DAMPAK UJARAN KEBENCIAN DI MEDIA SOSIAL PADA PENGGUNAAN BAHASA INDONESIA PADA WARGA KEPUNDUHAN
}

\author{
Rosalina Subekti ${ }^{1}$, Primadina Anismaditya ${ }^{2}$,Sesya Dias Mumpuni ${ }^{3}$ \\ ${ }^{1,3}$ Program Studi Bimbingan dan Konseling, Fakultas Keguruan dan Ilmu Pendidikan, Universitas \\ Pancasakti Tegal, Indonesia \\ ${ }^{2}$ Program Studi Manajemen, Fakultas Ekonomi dan Bisnis, Universitas Pancasakti Tegal, Indonesia \\ e-mail: ${ }^{1}$ rosalinasubekti@upstegal.ac.id, ${ }^{2}$ primadina@upstegal.ac.id, ${ }^{1}$ dias.mumpuni@upstegal.ac.id
}

\begin{abstract}
ABSTRAK
Masyarakat perlu mengetahui apa itu berita hoax untuk mencegah atau mengurangi dampak negatif dari berita hoax tersebut, serta bersikap lebih bijaksana dalam menanggapi perkembangan teknologi informasi dan menelaah kebenaran dari informasi sebelum dibagikan ke orang lain. Cepatnya penyebaran informasi tetap perlu disikapi dengan tenang dan jernih. Masyarakat harus lambat dalam mempercayai informasi yang diperoleh dengan memastikan kembali ke beberapa sumber yang terpercaya. Adanya "Sosialisasi Anti Hoaks" ini bertujuan untuk mengenalkan kepada warga Desa Kepunduhan Kecamatan Kramat Kabupaten Tegal. Memberikan sosialisasi kepada warga Desa Kepunduhan Kecamatan Kramat Kabupaten Tegal akan pentingnya mengakses berita. Untuk solusinya sendiri masyarakat tentu harus menyaring berita terlebih dahulu tidak langsung mensharringnya. Tentu jika hal demikian bisa dilakukan akan sedikit mengurangi berita hoaks dimedia sosisal seperti facebook. Twitter, Instagram, Whatshap, dan media sosial lainnya. Dan diharapkan masyarakat harus sedikit pandai menilai mana yang berita hoaks bohongan alias rekayasa dan mana yang real nyata kebenarannya.
\end{abstract}

Kata Kunci: hoaks, ujaran kebencian, bahasa, berita bohong, masyarakat

\begin{abstract}
The public needs to know what hoax news is to prevent or reduce the negative impact of the hoax news, and be more prudent in responding to the development of information technology and examine the truth of information before it is shared with others. The rapid spread of information still needs to be addressed calmly and clearly. The community must be slow in trusting the information obtained by ensuring return to several trusted sources. The existence of "Anti-Hoaks Socialization" aims to introduce the residents of the Village of the Subdistrict of Kramat District of Tegal Regency. Providing socialization to the residents of the Village of Obligation of the District of Kramat Tegal Regency of the importance of accessing news. For its own solution, the community must of course filter the news first, not directly address it. Of course if this can be done it will slightly reduce news on social media such as Facebook. Twitter, Instagram, Whatshap and other social media. And it is hoped that the public should be a little smart at evaluating which hoax hoaxes are fabricated and which are real truths.
\end{abstract}

Keywords: hoaks, hate speech, language, hoaxes, society

\section{PENDAHULUAN}

Begitu banyak ujaran kebencian, berita bohong dan akses konten negatif yang semakin meresahkan warga masyarakat. Generasi yang akan datang menjadi tantangan terbesar bagi bangsa ini. Keteladanan yang patut diberikan sangat menentukan para generasi ini untuk terus dapat mempelajari hal yang bermanfaat bagi dirinya. Seperti pada berita hoaks yang terjadi pada kalangan pengguna media sosial yang mengandung ujaran kebencian "As online content continues to grow, so does the spread of hate speech. We identify and examine challenges faced by online automatic approaches for hate speech detection in text. Among these difficulties are subtleties in language, differing definitions on what constitutes hate speech, and limitations of data availability for training and testing of these systems."'[1] Penyebaran berita hoaks yang sangat cepat didukung oleh kemajuan teknologi yang ada. Hampir setiap orang memiliki 
perangkat gawai yang dapat mengakses berbagai macam hal, tidak terkecuali konten hoaks. Pada tahun 2016, dari 256,2 juta jiwa penduduk Indonesia, terdapat 132,7 juta jiwa yang sudah terhubung ke internet. Konten yang paling banyak diakses oleh masyarakat Indonesia adalah media sosial. “

Kementerian Komunikasi dan Informatika (Kemenkominfo) mengungkapkan pengguna internet di Indonesia saat ini mencapai 63 juta orang. Dari angka tersebut, 95 persennya menggunakan internet untuk mengakses jejaring sosial. Direktur Pelayanan Informasi Internasional Ditjen Informasi dan Komunikasi Publik (IKP) , Selamatta Sembiring mengatakan, situs jejaring sosial yang paling banyak diakses adalah Facebook dan Twitter. Indonesia menempati peringkat 4 pengguna Facebook terbesar setelah USA, Brazil, dan India. Banyaknya sosial media yang juga diakses oleh masyarakat di Indonesia hampir sama dengan beberapa negara tersebut "This study considers the ways that overt hate speech and covert discriminatory practices circulate on Facebook despite its official policy that prohibits hate speech."[2]. Ujaran kebencian juga dapat memicu adanya diskriminasi yang lebih tajam.

Dampak dari informasi yang menyesatkan berupa Hoax telah terasa saat ini dengan hilangnya kepecayaan masyarakat terhadap lembaga/instansi pemerintah, timbulnya rasa cemas, munculnya kekhawatiran, ketakutan, rasa curiga, hilangnya rasa saling percaya, permusuhan dan terdegradasinya etika serta sopan santun di masyarakat.Beberapa ciri berita tersebut Hoax di antaranya adalah fakta atau data yang dilebih-lebihkan (hiperbolis), bagian terpenting sebuah berita yang dihilangkan, judul yang tidak sesuai dengan isi, ketidaksesuaian antara isi tulisan dengan foto, daur ulang peristiwa atau foto yang lama demi meramaikan isu-isu yang sedang berkembang. "The ways that 'hate' groups utilize the Internet and their purposes in doing so are then analysed, with the content and the functions of their websites as well as their agenda examined. Finally, the article explores the connection between hate speech and hate crime."[3]. Setidaknya ada beberapa langkah yang dapat dilakukan untuk menangkal hoax agar tidak berkembang menjadi bola api liar diantaranya dengan melakukan cek dan ricek informasi yang diterima dengan mencari sumber informasi didapat, memeriksa identitas penulis/penyunting informasi kemudian membandingkan berita yang diperoleh dengan yang ada di media mainstream. Secara sederhana staf Ahli Kementerian Komunikasi dan Informatika bidang hukum, Henry Subiyakto mengatakan agar masyarakat terlebih dahulu, "Saring sebelum Sharing". "Hate speech is an offensive kind of communication mechanism that expresses an ideology of hate using stereotypes. Hate speech targets different protected characteristics such as gender, religion, race, and disability. Control of hate speech can be made using different national and international legal frameworks."[4]. Dalam hal ini juga ujaran kebencian sangat berdampak pada gender, agama, ras bahkan pada orang-orang disabilitas.

Bahwasanya banyak orang berbagi empati wanita ini dengan korban potensial dari perkataan yang mendorong kebencian, namun tidak yakin bahwa menindas ucapan yang berbahaya adalah kejahatan yang lebih rendah. Bahkan orang-orang yang menjadi sasaran serangan ini telah mengungkapkan keraguannya. Dengan kata lain ujaran kebencian merupakan kejahatan menindas mengucapkan sesuatu yang dapat menyakiti dan merugikan orang lain. "The offensive posts are only subsequently removed if the complaints are upheld; therefore, they still cause the recipients psychological harm. In addition, this approach has frequently been criticised for delimiting freedom of expression, since it requires the service providers to elaborate and implement censorship regimes."[5]. Berbagai bentuk ungkapan yang menyakitkan dalam bentuk ekspresi maupun dengan kondisi yang lebih merugikan lagi.

Dalam berbahasapun juga akan mengalami dampak yang cukup terasa. Apalagi dalam penggunaan Bahasa Indonesia yang menjadi bahasa komunikasi sehari-hari masyarakat selain bahasa Tegal di Desa Kepunduhan. Menjadi pembelajaran bersama bahwa bahasa dapat menyampaikan maksud dari orang yang berbicara "Saat ini adalah era millennial, masa adanya peningkatan penggunaan dan keakraban dengan komunikasi, media dan teknologi digital. Hal tersebut berdampak pada perkembangan bahasa Indonesia. Keadaan yang ada sekarang adalah fungsi bahasa Indonesia mulai digantikan atau tergeser oleh bahasa asing dan adanya perilaku yang cenderung menyelipkan istilah asing, padahal padanan dalam bahasa Indonesianya ada, 
dikarenakan sikap yang meyakini bahwa akan terlihat modern, dan terpelajar dan dengan alasan mempermudah komunikasi di era millennial."[6]. Maksud dari jurnal diatas, dapat disimpulkan bahwasannya Ucapan kebencian, "kata-kata yang digunakan sebagai senjata untuk menyergap, meneror, melukai, menghina, dan merendahkan," merusak "tidak hanya kelompok yang ditargetkan atau keadaan fisiologis dan emosional individu, tetapi juga kebebasan pribadi, martabat, dan kepribadian" dan masyarakat pada umumnya.

Dengan pengetahuan masyarakat yang masih minim, maka penggiringan opini melalui berita bohong (hoax) sangat mudah sekali dilakukan. faktor utama yang menyebabkan informasi (hoax) mudah tersebar di indonesia adalah karakter masyarakat indonesia yang dinilai belum terbiasa berpendapat atau berdemokrasi secara sehat. Dalam pendidikan terutama, penggunaan Bahasa Indonesia juga menjadi penting "Sebagai bangsa yang dibangun atas dasar keberagaman suku bangsa dan budaya, Indonesia memiliki modal yang baik dalam memupuk rasa nasionalisme dan memperkuat identitas kebangsaan melalui penggunaan bahasa Indonesia. Dengan begitu, setiap masyarakat Indonesia akan memiliki identitas kesukuan dan identitas nasional yang kuat sebagai bagian dari bangsa Indonesia.'[7]. Maka perlu adanya suatu pendidikan di masyarakat khususnya dalam kesehariannya dalam menggunakan perangkat gawai. Kearifan dan kebijaksanaan dalam mengakses berita maupun komentar di sosial media sangat dibutuhkan dalam situasi Indonesia sekarang ini.

Keberagaman suku, agama, ras dan etnis menjadi potensi besar dalam kekokohan bangsa negara ini. Sikap toleransi dan memahami sesama sangat dibutuhkan dalam pembangunan diri demi kemajuan bersama. "By interviewing six elementary school teachers, this exploratory study examined how teachers describe refugee ELLs' social-emotional competencies and what pedagogical methods they report using with refugee ELLs for their social-emotional skills development"[8], hal ini juga berpengaruh pada sosial emosional dari pengguna sosial media. Desa Kepunduhan yang terletak di Kecamatan Kramat Kabupaten Tegal memiliki potensi yang sangat baik para warganya dalam mengakses dan memiliki perangkat gawai. Kemajuan di kotakota besar memiliki pengaruh yang signifikan pada daerah disekitarnya. "Pengaruh arus globalisasi dalam identitas bangsa tercermin pada perilaku masyarakat yang mulai meninggalkan bahasa Indonesia dan terbiasa menggunakan bahasa gaul. Saat ini jelas di masyarakat sudah banyak adanya penggunaan bahasa gaul dan hal ini diperparah lagi dengan generasi muda Indonesia juga tidak terlepas dari pemakaian bahasa gaul."[9].

Arus globalisasi juga membawa pengaruh terhadap penggunaan bahasa Indonesia bagi masyarakat. Salah satunya dalam penggunaan alat komunikasi dalam berinteraksi di kehidupan sehari-hari. [10] Interaksi tersebut dapat dilakukan diberbagai tempat misalnya di tempat pembelajaan, tempat sekolah, pasar, dan sebagainya. Dalam percakapan menggunakan bahasa Indonesia yang baik dan benar terkadang dicampurkan dengan bahasa daerah atau dalam linguistik (ilmu bahasa) sering disebut campur kode. Campur kode sering terjadi dalam percakapan sehari-hari misalnya di pasar. [11] Fenomena tersebut merupakan gejala percakapan yang mempengaruhi penggunaan bahasa Indonesia yang baik dan benar. Gejala tersebut dapat terjadi diberbagai lini masyarakat baik di kota maupun desa.

Desa yang memilliki kesadaran akan internet menjadi pelopor bagi masyarakat luas. Tidak hanya untuk kalangan Desa Kepunduhan saja, namun dapat memberikan manfaat kepada dunia luas melalui kesadaran dalam bersosial media. "While online abuse is largely understood as "hate speech," we make two interventions to problematize the presuppositions of this widely invoked concept. First, extreme speech emphasizes the need to contextualize online debate with an attention to user practices and particular histories of speech cultures. Second, related to context, is the ambiguity of online vitriol, which defies a simple antonymous conception of hate speech versus acceptable speech.'[12]. Sejalan dengan nawacita Indonesia generasi anti hoaks, maka sosialisasi dilakukan oleh berbagai lembaga negara salah satunya adalah Polri. Dalam situs www.humas.polri.go.id "Di dalam islam penyebar hoaks itu adalah dosa dan lebih kejam dari pembunuhan, oleh karena itu jangan kita mengikuti provokator-provokator tersebut tapi kita harus ikuti inspirator bangsa yang dapat memajukan bangsa". 
Di Polres Tegal deklarasi anti hoaks sudah berlangsung dari bulan Mei 2018 yang menggalang keikutsertaan warga masyarakat Kabupaten Tegal dari berbagai kalangan. Tidak terkecuali sosialisasi anti hoaks yang diadakan di Desa Kepunduhan Kecamatan Kramat Kabupaten Tegal. "Using the most egregious form of hate speech that has been prosecuted as an international crime - that of direct and public incitement to genocide - as a baseline, the author analyses the legal parameters of hate speech as persecution (a crime against humanity) and hate speech as instigation (a mode of liability)"[13]. Hal ini ujaran kebencian juga dapat berakibat ke ranah hukum. Adanya hukum di Indonesia dalam memberikan efek bagi para penyitas ujaran kebencian.

\section{METODOLOGI PENELITIAN}

Dilihat dari presentasi kehadiran masyarakat pada saat "Sosialisasi Anti Hoaks" dari keseluruhan analisis situasi yang belum nampak yaitu kurangnya rasa keingintahuan masyarakat terkait dengan Hoaks. Dibuktikan pada saat berlangsungnya agenda "Sosialisasi Anti Hoaks" masyarakat hanya $10 \%$ yang menghadiri agenda tersebut. Padahal peneliti berharap banyak akan kehadiran masyarakat yang antusias akan agenda ini. Dengan tujuan Memberikan sosialisasi kepada warga Desa Kepunduhan Kecamatan Kramat Kabupaten Tegal akan pentingnya mengakses berita.

Tabel 1. Jumlah Penduduk Berdasarkan Usia

\begin{tabular}{ccccc}
\hline Kelompok Usia & $0-5$ Tahun & 6-20 Tahun & 21-60 Tahun & 60 Tahun Keatas \\
\hline Jumlah Jiwa & 647 & 1.061 & 2.048 & 744 \\
\hline
\end{tabular}

Sumber : Data Monografi desa Kepunduhan Tahun 2017

Dari tabel jumlah kepundudukan masyarakat Desa Kepunduhan dari berbagai usia dapat dilihat bahwa kelompok usia 0-5 tahun berjumlah 647 jumlah jiwa, kelompok usia 6-29 tahun berjumlah 1.061 jumlah jiwa, kelompok usia 21-60 tahun berjumlah 2.048 jumlah jiwa, dan kelompok usia 60 tahun ke atas berjumlah 744 jumlah jiwa, dari tabel kependudukan diatas dapat diketahui bahwasannya kurannya rasa keingintahuan masyarakat akan Hoaks sangat rendah.

Mungkin hal tersebut dipengaruhi oleh pekerjaan masyarakat pada umumnya yaitu bertani/ bercocok tanam. Yang umumnya bertani itu pada pagi hari dan berhubung agenda "Sosialisasi Anti Hoaks' dimulai pada pagi hari juga yaitu pada jam 08.00 dan faktor tersebutlah yang mempengaruhi ketidakhadiran masyarakat dalam penelitian ini.

\section{HASIL DAN PEMBAHASAN}

\section{Hasil Penelitian}

Kegiatan dengan membuka acara dengan mengucapkan salam dan sambutan meriah di jawab oleh para peserta sosialisasi anti hoaks, untuk membuat peserta mencintai negaranya sendiri dan menghargai jerih payah perjuangan para pahlawan acara selanjutnya ialah menyayikan lagu Indonesia raya dengan di iringi dengan instrumental music. Rasa getar pada saat instrument tersebut di putar membuat rasa bangga pada diri panitia dan juga para peserta sosisalisasi karena menyayikan lagu Indonesia raya dengan penuh semangat serta antusis. Di sambung dengan sambtan ketua atau yang mewakili, dosen atau yang mewakili membuat suasana hening terasa sekali pada saat itu, warga pun menyimak dengan seksama dan di lanjutkan dengan sambutan kepala desa atau yang mewakili, karena kepala desa berhalangan hadir, tetapi hal tersebut tidak menjadikan kami patah arah serta kecewa, keyakinan kami ialah tidak akan mungkin kepala desa tidak hadir jika benar - benar kepentingan tersebut tidak sangat mendesak. Pengulangan kata kata saya mewakili kepala desa terus di uatarakan guna memahamkan peserta dan juga kami 
sebagai agar tidak merasa kecewa yang membuat kami akan menjadi terpuruk, setelah selesai acara sambutan di lanjutkan dengan pemateri 1 dari kassubag humas polres Tegal yang membawakan materi anti hoaks polisi, pembicara 2 dari kasatbinmas polres Tegal membawkan judul masyarakat anti hoaks dan yang terakhir ialah pembicara 3 dari universitas pancasakti Tegal membawakan tema anti hoaks secara global di sambung dengan Tanya jawab kepada peserta yang belum dapat memahami hoaks dengan penuh setelah acara tersebut selesai kami pun menutup acara dengan penuh kegembiraan, di lanjutkan dengan foto bersama dengan beberapa peserta untuk dapat mendokumentasikan suatu momentum yang langka ini.

Kemudian setelah acara kegiatan selesai kami dari membersihkan semua sampah dan merapihkan kembali segala peralatan yang telah digunakan untuk acara kegiatan. Namun pada saat melakukan membersihkan sampah sangat disayangkan karena warga Desa Kepunduhan tidak ikut membantu untuk membersihkan sampah dan hanya beberapa warga yang ikut membantu untuk merapikan sarana dan prasana seperti kursi, meja, dan sound sistem, dengan hal ini nantinya kami berharap warga Desa Kepunduhan untuk kedepannya supaya lebih memperhatikan tentang kebersihan di lingkungannya.

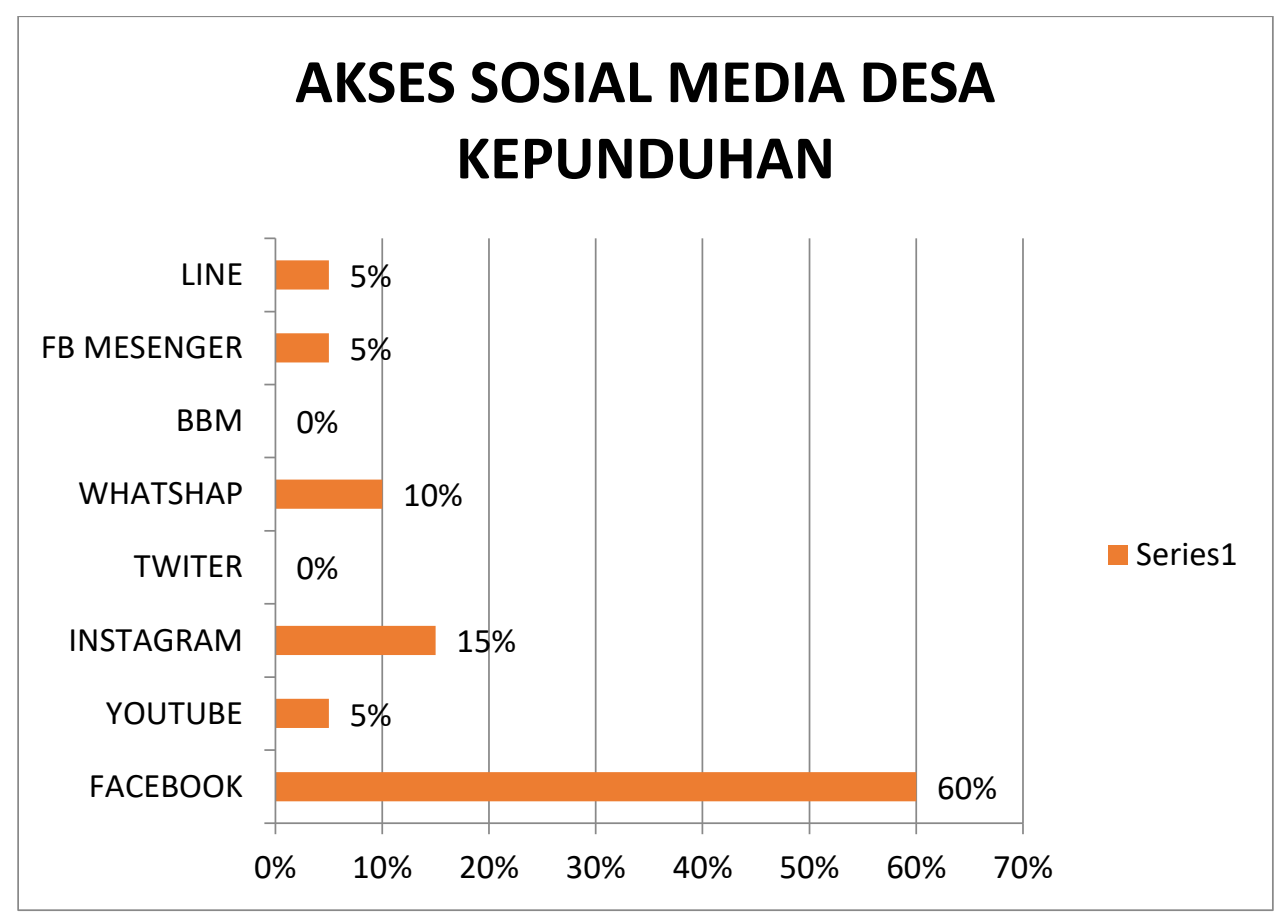

Gambar 1. Akses Sosial Media Desa Kepunduhan

Akses sosial media yang sering digunakan oleh warga desa kepunduhan kebanyakan adalah Facebook, 60\% dari keseluruhan warga desa kepunduhan facebook menjadi medsos pilihan pertama yang biasa digunakan oleh remaja dan dewasa khususnya warga desa kepunduhan. Facebook menjadi sosmed terbesar didunia yang sering digunakan kebanyakan orang, oleh karena itu diharapkan warga desa kepunduhan dapat memanfaatkan media sosial facebook ke hal-hal yang bermanfat untuk diri sendiri maupun untuk orang lain. 


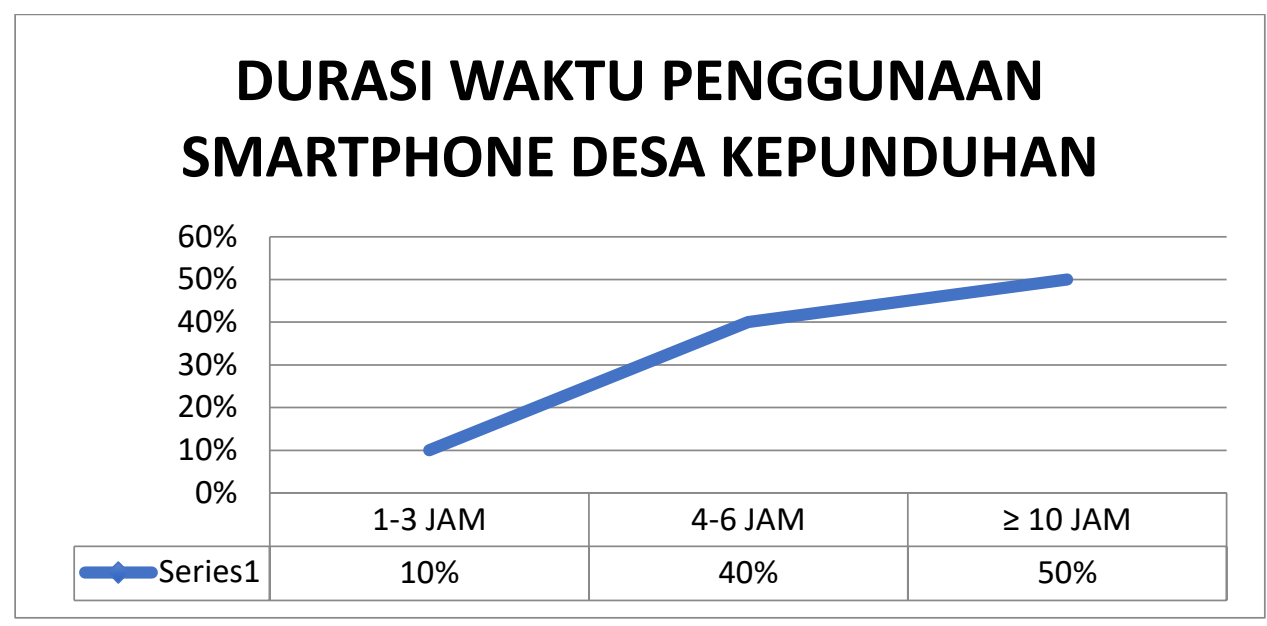

Gambar 2. Durasi Waktu Penggunaan Smartphone Desa Kepunduhan

Berdasarkan survei yang telah dilakukan, durasi waktu penggunaan smartphone warga desa kepunduhan yaitu lebih dari 50\% warga desa kepunduhan menggunakan smartphone dengan rentang waktu penggunaan lebih dari $10 \mathrm{jam}$, dan tidak sedikit pula $40 \%$ warga desa kepunduhan juga menggunakan smartphone dengan durasi waktu 4-6 jam dan hanya 10\% yang megunakan smarphone dalam waktu 1-3 jam.

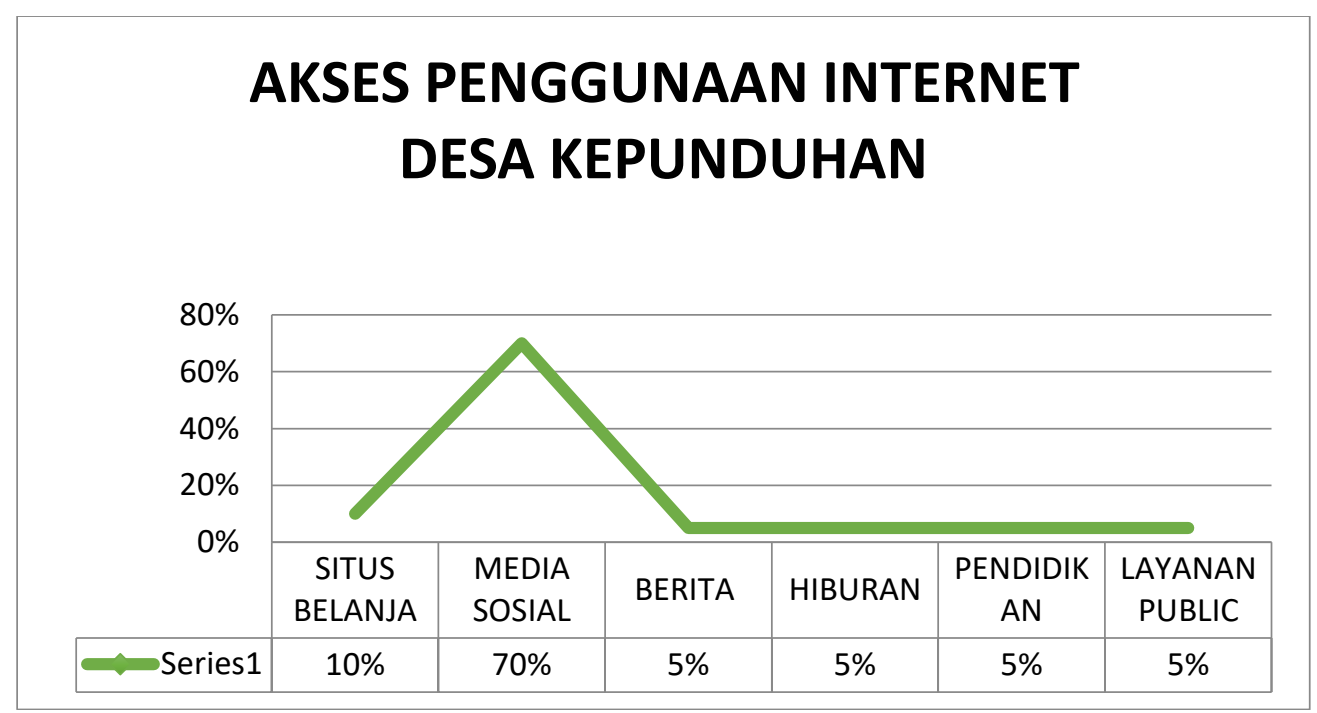

Gambar 3. Akses Penggunaan Internet Desa Kepunduhan

Akses penggunaan internet warga desa kepunduhan $70 \%$ didominasi oleh penggunaan sosial media, $10 \%$ situs belanja, $5 \%$ berita, $5 \%$ hiburan, $5 \%$ pendidikan, $5 \%$ layanan public. Data diatas diketahui dari penelitian yang sudah dilakukan secara langsung pada warga desa kepunduhan.

\section{Pembahasan}

Dalam pelaksanaan kegiatan "Sosialisasi Anti Hoaks" rencana tahapan selanjutnya yaitu pada saat acara kegiatan selesai kami Desa Kepunduhan memberikan contoh saat ahir dari acara kegiatan "Sosialisasi Anti Hoaks" kami dari juga memberikan contoh dengan cara membersihkan seluruh sampah yang ada di sekitar tempat acara kegiatan "Sosialisasi Anti Hoaks", namun dalam kegiatan membersihkan sampah yang ada di sekitar tempat kegiatan dari masyarakat Desa Kepunduhan tidak terlihat warga yang ikut membantu kami dari untuk membersihkan sampah, warga terlihat tidak perduli dengan sampah-sampah yang berserakan dan cenderung lebih 
Jurnal SEMANTIKA, Volume 2, No. 01, Agustus 2020, pp. 44-51

meninggalkan tempat kegiatan dan pulang ke rumah masing-masing. Begitupun peserta didik SD Negeri 01 Kepunduhan \& SD Negeri 02 Kepunduhan terlihat membuang sampah sembarangan dan tidak ikut serta untuk membersihkannya Oleh karena itulah kami dari mencotohkan hal-hal yang menurut masyarakat Desa Kepunduhan tidak penting tetapi hal itu merupakan suatu yang penting karena dengan membersihkan sampah nantinya juga akan berdampak positif bagi seluruh warga Desa Kepunduhan dan memberikan kebersihan di Desa Kepunduhan, maka dari itu kami dari berharap supaya warga Desa Kepunduhan nantinya dapat melaksanakan kegiatan yang telah kami contohkan dengan baik dan diharapakan supaya bisa memberikan contoh kepada warga tetangga desa di sekitar kecamatan Kramat.

Dengan adanya acara kegiatan juga mengharapkan kebersamaan antar sesama warga yang ada di Kecamatan Kramat khususnya Desa Kepunduhan lebih kompak lagi warganya. Dan setelah mengikuti kegiatan "Sosialisasi Anti Hoaks" diharapkan masyarakat jadi lebih jeli lagi dalam menyaring informasi dan tidak sembarang dalam mensharingnya. Dan juga memberikan sosialisasi kepada warga Desa Kepunduhan Kecamatan Kramat Kabupaten Tegal akan pentingnya mengakses berita. Intinya setelah masyarakat Kepunduhan dan adek-adek peserta didik SD Negeri 01 Kepunduhan dan SD Negeri 02 Kepunduhan mengikuti "Sosialisasi Anti Hoaks" selanjutnya diharapkan harus lebih pandai dalam menyaring berita dan bisa membedakan mana berita bohong dan berita real nyata terbukti kebenarannya. Dalam menghadapi banyaknya opini, berita, atau informasi yang diterima, masyarakat diharapkan dapat lebih siap, cerdas dan bijak.Berikut beberapa hal yang harus diperhatikan sebelum mempublikasikan sesuatu di media sosial (Pratama, 2016):

- Pastikan kebenaran informasi

- Menghindari hal yang dilarang UU ITE

- Menghadirkan nilai yang sesuai

- Post dalam kondisi tenang

\section{SIMPULAN}

Masyarakat perlu mengetahui apa itu berita hoax untuk mencegah atau mengurangi dampak negatif dari berita hoax tersebut, serta bersikap lebih bijaksana dalam menanggapi perkembangan teknologi informasi dan menelaah kebenaran dari informasi sebelum dibagikan ke orang lain. Cepatnya penyebaran informasi tetap perlu disikapi dengan tenang dan jernih. Masyarakat harus lambat dalam mempercayai informasi yang diperoleh dengan memastikan kembali ke beberapa sumber yang terpercaya. Adanya "Sosialisasi Anti Hoaks" ini bertujuan untuk mengenalkan kepada warga Desa Kepunduhan Kecamatan Kramat Kabupaten Tegal akan adanya. Memberikan sosialisasi kepada warga Desa Kepunduhan Kecamatan Kramat Kabupaten Tegal akan pentingnya mengakses berita. Untuk solusinya sendiri masyarakat tentu harus menyaring berita terlebih dahulu tidak langsung mensharringnya. Tentu jika hal demikian bisa dilakukan akan sedikit mengurangi berita hoaks dimedia sosisal seperti facebook. Twitter, instagram, Whatshap, dan media sosial lainnya. Dan diharapkan masyarakat harus sedikit pandai menilai mana yang berita hoaks bohongan alias rekayasa dan mana yang real nyata kebenarannya.

\section{REFERENCES}

[1] S. MacAvaney, H. R. Yao, E. Yang, K. Russell, N. Goharian, and O. Frieder, "Hate speech detection: Challenges and solutions," PLoS One, vol. 14, no. 8, 2019, doi: 10.1371/journal.pone.0221152.

[2] A. Ben-David and A. Matamoros-Fernández, "Hate speech and covert discrimination on social media: Monitoring the Facebook pages of extreme-right political parties in Spain," Int. J. Commun., vol. 10, 2016. 
[3] R. Cohen-Almagor, "Taking North American White Supremacist Groups Seriously: The Scope and Challenge of Hate Speech on the Internet," International Journal for Crime, Justice and Social Democracy, vol. 7, no. 2. 2018, doi: 10.5204/ijcjsd.v7i2.517.

[4] N. Chetty and S. Alathur, "Hate speech review in the context of online social networks," Aggression and Violent Behavior, vol. 40. 2018, doi: 10.1016/j.avb.2018.05.003.

[5] S. Ullmann and M. Tomalin, "Quarantining online hate speech: technical and ethical perspectives," Ethics Inf. Technol., vol. 22, no. 1, 2020, doi: 10.1007/s10676-019-09516$\mathrm{z}$.

[6] N. P. Putri, "Eksistensi Bahasa Indonesia Pada Generasi Millennial," Widyabastra, vol. 05, no. 1, 2017.

[7] D. Rumandang Bulan, "Bahasa Indonesia Sebagai Identitas Nasional Bangsa Indonesia," J. jisipol, vol. 3, 2019.

[8] H. Cho, X. C. Wang, and T. Christ, "Social-Emotional Learning of Refugee English Language Learners in Early Elementary Grades: Teachers' Perspectives," J. Res. Child. Educ., vol. 33, no. 1, 2019, doi: 10.1080/02568543.2018.1531449.

[9] A. P. Rahayu, "Menumbuhkan bahasa Indonesia yang baik dan benar dalam pendidikan dan pengajaran," J. Paradig., vol. 2, no. 1, 2015.

[10] Nurpratiwiningsih, Laelia, "Pengaruh Globalilisasi terhadap Penggunaan Bahasa Indonesia bagi Masyarakat," J. Kontekstual, vol.1, n0. 02, 2020.

[11] Kurniawan, Prasetyo Yuli dan Ikfi Rizqi Amaliyah, "Analisis Gejala Linguistik dalam Ranah Perdagangan Desa Jatimakmur, " Jurnal Semantika, vol.1, no.02, 2020.

[12] M. Pohjonen and S. Udupa, "Extreme speech online: An anthropological critique of hate speech debates," Int. J. Commun., vol. 11, 2017.

[13] A. Fino, "Defining Hate Speech," J. Int. Crim. Justice, vol. 18, no. 1, 2020, doi: 10.1093/jicj/mqaa023. 